\title{
O historiador Gonzalo Vial e a construção do Marco Político do Informe Rettig (1991)
}

Lays Corrêa da Silva ${ }^{1}$

Resumo: O presente artigo tem por objetivo analisar o papel do historiador Gonzalo Vial na construção do Marco Político do Informe da Comisión Nacional de Verdad y Reconciliación Chilena, conhecido como Informe Rettig. Tal seção do documento foi dedicada a tratar dos eventos anteriores ao golpe de Estado de 1973. A narrativa contida no Marco Político do Informe reforça a ideia de inevitabilidade do golpe, utilizando-se da teoria historiográfica de Gonzalo Vial de que a quebra da democracia no Chile se deu a partir da "quebra de consensos" que já vinha acontecendo desde o início do século, mas que se intensificou com a eleição de Allende em 1970. Buscaremos, portanto, refletir sobre os usos do passado recente chileno e sobre o papel do historiador na construção de uma memória oficial que permitisse a reconciliação entre os chilenos, necessária para a consolidação democrática do governo de Aylwin.

Palavras-chave: Disputas de memória; Comissões da Verdade; Chile

\section{The historian Gonzalo Vial and the construction of the Political Framework of the Rettig Report (1991)}

\begin{abstract}
The purpose of this article is to analyze the role of the historian Gonzalo Vial in the constuction of the Political Framework of the Report of the Chilean's Comision Nacional de Verdad y Reconciliación, known as Informe Rettig. This section of the document was dedicated to dealing with the events before the coup of 1973. The narrative contained in the Political Framework of the Report reinforces the idea of the inevitability of the coup, using Vial's theory that the breakdown of democracy in Chile occurred from the "breakdown of consensus" that had been happening since the beginning of the century, but which intensified with the election of Allende in 1970. We will therefore seek to reflect on the uses of the recent Chilean past and on the role of the historian in the construction of an official memory that would allow the reconciliation between Chileans, necessary for the democratic consolidation of the Aylwin government.
\end{abstract}

Keywords: Memory disputes; Truth Commissions; Chile

\footnotetext{
${ }^{1}$ Doutoranda do Programa de Pós-graduação em História Social da Universidade Federal do Rio de Janeiro (PPGHIS/UFRJ). Título da pesquisa em andamento: "Manifiesto de Historiadores no Chile: trajetória de intelectuais, renovação historiográfica e disputas de memória (1980-1990)". Esta pesquisa foi desenvolvida com o apoio da FAPERJ Nota 10 durante o mestrado. E-mail: layscorrea.s@gmail.com.
} 
Artigo recebido em: 28/06/2020

Artigo aprovado para publicação em: 21/09/2020

Durante todo o processo de transição política chilena, o termo "reconciliação" esteve presente no discurso dos principais atores políticos que atribuíam distintos significados a essa expressão. O termo chegou inclusive a ser usado pelo próprio regime militar em um sentido de encerrar os assuntos do passado e seguir em frente sem olhar para trás. Reconciliação, nesse sentido, significava esquecimento. Já para os organismos de Direitos Humanos e as Agrupações de Familiares de Vítimas, reconciliação passava pelo esclarecimento da verdade e pelo julgamento dos culpados.

Tendo feito da reconciliação o lema de seu governo, o primeiro presidente eleito com a volta da democracia, Patricio Aylwin, teve de enfrentar os entraves impostos pela Ditadura para avançar em uma proposta de reconciliação que não colocasse em risco a nova democracia, mas que também enfrentasse a questão das violações de Direitos Humanos.

Uma das primeiras medidas tomadas pelo governo nesse sentido foi a implementação da Comisión Nacional de Verdad y Reconciliación com o objetivo de esclarecer a verdade sobre "las graves violaciones a los derechos humanos cometidas en el país entre el 11 de septiembre de 1973 y el 11 de marzo de 1990" (CHILE, 1990). Em dois anos de trabalho, a Comissão investigou os casos de "desapariciones de personas detenidas, ejecuciones, torturas con resultado muerte cometidos por agentes del Estado o personas al servicio de éstos, secuestros y atentados contra la vida de las personas ejecutados por particulares bajo pretextos políticos" (CHILE, 1990), sem, no entanto levar à julgamento os culpados, já que a Lei de Anistia de 1978 impedia o julgamento dos crimes ocorridos entre 1973 e 1978.

Dessa forma, a reconciliação ia se convertendo em uma proposta que

Se basaba en la impunidad jurídica de ciertos crímenes y en los indultos para otros, las reintegraciones y reconfiguraciones políticas, las reparaciones y pensiones de distinta índole para compensar, dentro de lo posible, a los vencidos de 1973. (LOVERMAN; LIRA, 2000, p. 490) 
A necessidade de reconciliar o país passava também pela necessidade de se conformar uma memória oficial sobre o passado autoritário. Nossa hipótese é de que essa tentativa de construção de uma memória oficial foi conduzida por meio da redação do Marco Político do Informe da Comisión Nacional de Verdad y Reconciliación, nosso principal objeto de estudo neste artigo. Essa seção, escrita pelo historiador conservador Gonzalo Vial, tratava do período anterior ao golpe de estado que, em 1973, derrubou o governo de Salvador Allende. Acreditamos não ser uma coincidência a escolha de Vial para construir essa narrativa. Gonzalo Vial era o único historiador entre os comissionados e tinha uma tese historiográfica que se baseava na ideia de "quebra de consenso". De acordo com essa tese, o Chile já vinha passando por uma crise política desde o início do século, entretanto, a eleição de Allende contribuiu para a acentuação da crise devido à polarização "provocada" pelo seu governo. Percebemos que essa tese de Vial está presente no texto do Informe como uma estratégia política: a de consolidar uma memória sobre o período do golpe de Estado que permitisse a reconciliação política por meio do reforço da teoria da "inevitabilidade" do golpe.

Ainda que exista uma vasta bibliografia sobre a Comissão e o próprio Informe, acreditamos ainda não ter sido muito explorado o papel do historiador Gonzalo Vial, assim como a relação entre o Marco Político do Informe com a tese historiográfica de Vial também não foi ainda tomada como objeto de estudo pelos pesquisadores. Nesse sentido, a pesquisa aqui apresentada pretende contribuir para os estudos sobre os usos políticos do passado evidenciando a dimensão pública do historiador e seu papel na formação de culturas históricas e memórias coletivas (BAUER, 2017).

Nosso artigo se divide da seguinte forma: antes de adentrar em uma análise do Marco Político do Informe, julgamos necessário tratar da trajetória política e intelectual de Gonzalo Vial, já que o historiador atuou nas "campanhas de terror" promovidas pela direita chilena para desestabilizar o governo de Allende, posteriormente tendo uma colaboração polêmica com a Ditadura Militar. Analisamos também a produção historiográfica do autor buscando entender a qual corrente historiográfica ele se filia. Depois, debatemos alguns pontos de sua atuação na Comissão para então entrarmos na 
análise do Marco Político do Informe comparando-o à tese de Vial. Queremos com este artigo

\begin{abstract}
Fugir da visão cômoda e apaziguadora, difundida pelo senso comum e não de todo abandonada na academia, segundo a qual a história, enquanto uma "ciência objetiva", estaria por ela mesma preservada dos impasses sociais e das disputas políticas que definem determinado contexto. Se o conhecimento, como Michel Foucault sugeriu, é menos uma faculdade humana inata do que um acontecimento e, como todo acontecimento, assume uma dimensão política, o gesto historiográfico, como forma de atuação pública, é ele também um gesto político, e pode assim ser encarado (BAUER; NICOLAZZI, 2016, p. 831-832).
\end{abstract}

\title{
A trajetória de Gonzalo Vial (1930-2009)
}

Vindo de uma família tradicional católica chilena, Gonzalo Vial iniciou seus estudos na Pontificia Universidad Católica de Chile em Direito e Pedagogia em História nos anos 1950, período de forte incidência dos setores médios na vida política, cultural e educacional do país (SUBERCASEAUX , 2008, p. 6). Dentro da Universidade, Vial conheceu aqueles que seriam suas duas principais referências: o advogado Jorge Prat e o historiador Jaime Eyzaguirre. O primeiro era professor de Direito, saído da Juventud Conservadora e militante do Partido Conservador. De Jorge Prat, Gonzalo herdou o nacionalismo acentuado de seu mentor, que ficava evidente já em suas publicações no jornal universitário nacionalista $M a ́ s^{2}$. Já Jaime Eyzaguirre era o principal representante da historiografia católica no Chile, corrente que exerceu forte influência na produção historiográfica de Vial.

Sua relação com a política começou ainda em 1954, quando Gonzalo atuou como secretário privado de Jorge Prat, então Ministro da Fazenda durante o segundo governo de Carlos Ibáñez. Sua atuação durou pouco, assim como a militância dentro do Partido Nacional. Juntamente a Prat, Vial participou da fundação em 1963 do Movimiento Acción Nacional, que pretendia levar a candidatura de Jorge Prat como uma opção alternativa ao processo eleitoral para presidência do Chile, proposta que acabou não vingando

\footnotetext{
${ }^{2}$ Disponível em <http://www.memoriachilena.gob.cl/602/w3-article-100642.html\#presentacion> Último acesso em 07 de fevereiro de 2019.
} 
(GONZÁLEZ, 2017, p. 27). Apesar dessas aparições iniciais na vida política chilena, sempre ligadas à influência de Prat, pode-se dizer que até 1969 o trabalho intelectual de Gonzalo Vial esteve restrito ao campo acadêmico, principalmente dentro da Pontificia Universidad Católica de Chile (GONZÁLEZ, 2017, p. 27). Foi a partir da fundação da revista Portada que Gonzalo iniciou uma nova etapa em sua trajetória intelectual.

Sobre esse período da vida de Vial, nossa principal fonte é o trabalho biográfico realizado pelo historiador Mario González, especialista da história recente do pensamento intelectual conservador chileno. Para o autor, o período da trajetória de Vial que se inicia em 1969 e vai até o golpe de 1973 esteve ligado à formulação de um projeto social para o Chile.

A revista Portada surgiu como continuação da revista Finis Terrae, fundada por Jaime Eyzaguirre em 1967 e também como uma resposta à conjuntura política e social de mobilização popular durante o governo do democrata cristão Eduardo Frei (GONZÁLEZ, 2017, p. 29). Portada foi uma revista que circulou em um ambiente restrito e cujas ideias eram dirigidas aos membros da classe dominante (GONZÁLEZ, 2017, p. 30). De acordo com o próprio Gonzalo Vial, a revista participou das “campañas del terror" que estavam sendo fomentadas na época:

Yo mismo participé en dos "campañas del terror" contra Salvador Allende, en
1964 y en 1970, escribiendo las cosas horribles que podían suceder en Chile si
llegaba a triunfar. Y esa campaña del terror era financiada por la CIA
diretamente. Yo no lo sabía, ni recibí ni un centavo por mis producciones
intelectuales. Pero se había generado una situación absolutamente poco
saludable en la política chilena (GONZÁLEZ, 2017, p. 42).

Com a chegada da Unidade Popular ao poder, em março de 1971, Gonzalo participou da fundação de uma segunda revista, a Qué Pasa, que, diferentemente da proposta da revista Portada, deveria ser uma publicação voltada às massas. A estratégia utilizada pela revista Qué Pasa era de evidenciar o tempo todo o perigo iminente de uma "ditadura comunista" no país. Grande parte do comitê editorial e dos colaboradores das duas revistas tiveram postos importantes durante os dez primeiros anos de Ditadura (GONZÁLEZ, 2017, p. 22). 
Podemos dizer que o grupo ideológico ao qual Gonzalo Vial estava filiado era aquele conhecido como "blando" formado por neoliberais e gremialistas ${ }^{3}$. Esses intelectuais participaram da formulação de uma nova economia política e de uma nova democracia, que deveria ser autoritária e protegida (GONZÁLEZ, 2017, p. 44-45), dentre eles, destaca-se o nome de Jaime Guzmán como principal teórico do regime militar. Os intelectuais envolvidos no projeto editorial da revista Qué Pasa não apenas criticavam o governo de Salvador Allende, mas também propuseram uma alternativa baseada na ideia de unidade nacional. Progressivamente, as Forças Armadas foram ocupando o lugar de "salvadores" dentro do projeto que esse grupo defendia.

Quando veio o golpe, em 1973, Gonzalo Vial ainda trabalhava na direção das duas revistas. Ele se recorda que, nesse momento de extrema polarização política, havia rumores todos os dias sobre um possível golpe:

\begin{abstract}
La noche del 10 estaba en la revista escribiendo hasta última hora —más de alguien no había cumplido con entregar a tiempo - cuando de repente aparece en mi escritorio Ricardo Claro. Se sienta al otro lado de la máquina, me mira, pero no me dice nada. El tenía la idea de que en la revista había un mar de micrófonos directamente conectados con La Moneda y bueno, saca un papel de su bolsillo y me lo muestra: "Mañana es el golpe", decía... y yo, que había oído mil veces el mismo cuento de que mañana viene el lobo, le di je: "Ya Ricardo, muchas gracias, pero por favor déjame terminar esto porque tengo que cerrar la revista". En verdad, el asunto me quedó dando vueltas y toda la noche la pasé nervioso. A la mañana siguiente - yo no tenía radio ni televisión, ¡fíjate el periodista! - me fui a "pata pelada" al auto y puse la radio. Estaban dando un programa que se llamaba «Desayuno en la Agricultura» y escuché que se estaba desarrollando en la más plena normalidad. ¡Otra vez — penséme contaron el cuento del golpe! Entonces me levanté para llevar a mis niños al colegio y no alcancé a llegar a la puerta de la parcela, donde vivía en ese tiempo, y oí el primer bando. La ignorancia de los civiles respecto al golpe era absoluta. $^{4}$
\end{abstract}

Com a instauração da Ditadura, Gonzalo esteve envolvido na redação do Libro Blanco del Cambio de Gobierno en Chile, que foi escrito e publicado pela Secretaria Geral de governo, logo após o golpe. O livro continha uma série de documentos, supostamente achados no gabinete de um dos Ministros de Allende, chamado de Plano

\footnotetext{
${ }^{3}$ Sobre o assunto ver: ORTIZ, Veronica. Nacionales y gremialistas: el "parto" de la nueva derecha política chilena, 1964-1973. Santiago: LOM Ediciones, 2008.

4 “Gonzalo Vial Correa 1930-2009: Historiador y protagonista de un siglo.", La Segunda, Santiago, 30 out. 2009, caderno especial, p. 4. Archivo de Referencias Críticas, Biblioteca Nacional Digital de Chile.
} 
Zeta. De acordo com esse plano, o governo de Salvador Allende preparava para o dia 19 de setembro um golpe que instalaria uma "República Popular Democrática no Chile":

El Libro Blanco debía impactar a la "opinión universal" haciendo pública y conocida que la acción de las Fuerzas Armadas desmontó un autogolpe planeado por la izquierda, cuyo objetivo era establecer una ditadura totalitaria, después de haber eliminado a una serie de militares y civiles opositores al gobierno de la Unidad Popular. Aparentemente, tras la fiesta popular se escondia una amarga y dolorosa sombra de terror (GONZÁLEZ, 2017, p. 60).

Gonzalo já deu diversas declarações sobre o livro, sendo que em 1999, admitiu ser um dos autores ${ }^{5}$. O plano, que acabou servindo como justificativa para os crimes cometidos pela Ditadura Militar, foi desmentido por posteriores investigações da CIA e de diversos historiadores. Ele foi na verdade um instrumento político utilizado para a guerra psicológica das Forças Armadas contra o comunismo ${ }^{6}$.

Em 1978, Gonzalo Vial foi chamado para ser Ministro da Educação em uma tentativa de "civilizar" o gabinete de Pinochet. Essa ideia partiu do então Ministro do Interior, Sergio Fernández, que buscava integrar o máximo possível de civis ao governo militar. Em sua última entrevista, em 5 de agosto de 2008, Gonzalo descreve sua experiência no governo: "Pésimo. Es un ministerio en que todavía no se puede hacer nada y en ese entonces no se podía hacer absolutamente nada, porque las 10 mil escuelas y liceos eran fiscales, y eran manejados teóricamente desde la Alameda, desde el propio Ministerio" 7 .

Durante o período em que esteve à frente do ministério, Gonzalo Vial defendeu que com relação ao ensino de História nos colégios, deveria ser enfatizada

la formación de la nacionalidad chilena y del pueblo de Chile; la unidad nacional; las grandes hazañas bélicas, económicas, culturales, cívicas del país y [...] [destacar] a sus mejores valores individuales, especialmente a quienes

\footnotetext{
${ }^{5}$ Disponível em: <http://www.memoriachilena.gob.cl/602/w3-article-100642.html> Último acesso em 07 de junho de 2020.

${ }^{6}$ Disponível em: <http://www.memoriachilena.cl/602/w3-article-96802.html> Último acesso em 07 de junho de 2020.

7 “Gonzalo Vial Correa 1930-2009: Historiador y protagonista de un siglo.”, La Segunda, Santiago, 30 out. 2009, caderno especial, p. 4.
} 
han sacrificado su vida e intereses en el servicio de la pátria (GONZÁLEZ, 2017, p. 109).

Seu tempo como Ministro da Educação foi curto, já que Gonzalo Vial se envolveu em uma polêmica com o general Manuel Contreras, ex-chefe da Dirección de Inteligencia Nacional (DINA), principal órgão da repressão ditatorial chilena. Segundo Vial, os Estados Unidos haviam pedido a extradição de Contreras para julgar acusações sobre o caso Letelier ${ }^{8}$. Gonzalo soube por seu companheiro de trabalho Sergio Fernandéz que o embaixador norte-americano havia se queixado para o chanceler Hernán Cubillos de que apesar de o governo chileno haver prometido total imparcialidade no caso, era o advogado-chefe do Ministério da Educação quem estava à frente da defesa de Contreras. Após esse episódio, Gonzalo Vial conversou com o advogado e lhe pediu que escolhesse se continuaria no Ministério ou defenderia o general. Nesse momento, então, Contreras acusa Vial à Junta Militar, criando um mal-estar dentro do governo, que acabou resultando no afastamento de Gonzalo 9 .

Recentemente, em um artigo publicado pelo jornal chileno The Clinic, Gonzalo Vial foi acusado de ter pressionado a Ditadura Militar a realizar uma operação de investigação sobre os antecedentes políticos de cerca de noventa mil professores de escolas e liceus públicos. Nos documentos apresentados pelo jornal, vemos uma carta de um professor endereçada ao ministro com reclamações sobre a ação de agentes do CNI na escola em que trabalhava. Tal operação teria sido motivada após a prisão do professor Federico Álvarez Santibáñez, conhecido militante do Movimiento de Izquierda

\footnotetext{
${ }^{8}$ Orlando Letelier, ex-chanceler e embaixador chileno em Washington durante o governo do presidente Salvador Allende, foi morto em 1976 por agentes secretos da DINA. Letelier foi assassinado em Washington, onde agentes da DINA colocaram bombas em seu carro, resultando na sua morte e na de sua assessora Ronnie Moffitt. O fato de a ação ter se dado em solo norte-americano fez com que o governo dos Estados Unidos deixasse de apoiar formalmente a ditadura pinochetista e cobrasse informações do governo chileno para a resolução do caso.

${ }^{9}$ CLAVEL, Patricia. Gonzalo Vial Correa 1930-2009: Historiador y protagonista de un siglo. La Segunda, Santiago, 30 out. 2009, caderno especial, p. 5. Archivo de Referencias Críticas, Biblioteca Nacional Digital de Chile.
} 
Revolucionario (MIR). Para Vial, a prisão de Santibáñez acendeu um alerta sobre a infiltração de professores marxistas na rede de ensino pública, que deveria ser contida ${ }^{10}$.

Apesar de sua polêmica participação no governo de Pinochet, Gonzalo foi um dos primeiros representantes da direita a denunciar publicamente os crimes de Direitos Humanos que estavam ocorrendo durante o regime. Ainda em meados dos anos 1970, enquanto era diretor da revista Qué Pasa, produziu um editorial intitulado "Faltan 113 chilenos" denunciando a Operação Colombo ${ }^{11}$. Mais tarde, em 1985, com um artigo em que se referia à "perversão ética" dentro do governo comparando-a a um câncer que havia se alastrado pela sociedade, denunciou os "asesinatos horribles" ocorridos entre 1979 e 1985. Essa mudança no posicionamento de Vial se deve, provavelmente, ao aumento das pressões internacionais após o caso Letelier e a crise na qual o governo se encontrava em meados dos anos 1980, com o aumento das mobilizações populares. Vale lembrar também que o segundo artigo de Vial foi publicado no mesmo ano em que a Argentina iniciou os juízos das Juntas Militares, marcando uma mudança na conjuntura latino-americana sobre a questão dos Direitos Humanos e abrindo um precedente para o julgamento das Ditaduras Militares instauradas. Se em um primeiro momento a repressão era justificada para combater o mal do comunismo, a permanência dessas práticas passou a colocar em risco a legitimidade da Ditadura e o projeto de uma democracia autoritária e protegida, como defendia Vial.

\section{Historiografia conservadora}

Como já foi mencionado, o traço nacionalista da produção de Vial se deve em grande parte às influências de Jorge Prat e Jaime Eyzaguirre em sua formação intelectual.

\footnotetext{
${ }_{10}$ Disponível em: <https://www.theclinic.cl/2015/06/02/gonzalo-vial-el-gran-espia-de-pinochet-y-la-cni/> Último acesso em 07 de junho de 2020.

11 A Operação Colombo foi uma ação conjunta entre Brasil, Chile e Argentina, considerada uma das precursoras da Operação Condor. Para encobrir a morte de militantes do MIR pela Ditadura, o governo espalhou a notícia de que esses teriam sido mortos por seus próprios companheiros numa tentativa de invadir o Chile. A notícia foi divulgada em jornais chilenos, brasileiros e argentinos. Para saber mais sobre a Operação Colombo, ver: QUADRAT, Samantha. Operação Condor: o "Mercosul” do terror. Estudos IberoAmericanos, v. 28, n. 1, junho 2002, p. 167-182.
} 
Eyzaguirre era um dos principais historiadores representantes da historiografia nacionalista-conservadora surgida no final do século XIX. De acordo com o historiador Julio Pintotal, a historiografia nacionalista-conservadora:

compartía el sentido nacionalista y elitista ostentado por sus predecesores liberales, pero tomaba distancia de algunos principios que, como el individualismo, el utilitarismo o el laicismo, juzgaba en no poca medida responsables de la decadencia en que se hallaba sumido el empuje y la convivecia nacional (VALLEJOS, 2016, p.21).

De acordo com essa tendência, o papel do historiador seria o de identificar a "alma nacional". Para Gonzalo Vial, a "alma nacional" chilena havia sido forjada durante o período colonial e por isso seus primeiros trabalhos historiográficos foram sobre esse período no Chile:

Los trabajos que Vial publicó hayan sido destinados a demostrar que durante la hegemonia española se había forjado la identidad chilena como un elemento fundador de la nacionalidad. Muy lejos de constituir un período "oscuro" de opresión y de falta de libertad, tal como se referia la historiografia liberal del siglo XIX, para Vial, en esa época se constituyó la ideia de pertenecer a una nación que avanzaba bajo un "destino común", que permitía a los chilenos y chilenas lograr superar las dificultades que se le presentaban de forma conjunta. Bajo esta perspectiva de análisis, Vial hizo una defensa tanto de la Conquista como de la Colonia, cuya matriz teórica fue una combinación de nacionalismo e hispanismo, influenciada de manera directa por Jaime Eyzaguirre, su mentor, Osvaldo Lira, e indirecta, por la corriente de intelectuales españoles contrarrevolucionarios como Vázquez de Mella, José Antonio Primo de Rivera, Ramiro de Maeztu, entre otros (GONZÁLEZ, 2017, p. 115).

Outra característica dessa historiografia era a "confianza en la intervención providencial de personajes de excepción, portadores del verdadero espíritu nacional" (VALLEJOS, 2016, p. 29-30). A figura desses personagens, como o líder dos conservadores durante a Guerra Civil de 1829-1830, Diego Portales, é constantemente destacada por esses historiadores. No caso de Vial, podemos identificar que essa tendência personalista esteve presente em seus trabalhos biográficos. Gonzalo Vial escreveu três biografias: uma sobre Arturo Prat, outra sobre Salvador Allende e a última sobre Augusto Pinochet. De acordo com o autor, a escolha por eles se deve pela sua importância para a história do Chile e pela simpatia que possuía por esses personagens. Gonzalo descreve seus trabalhos biográficos da seguinte forma: 
Para escribir una buena biografía hay que tener algún cariño por el biografiado, una simpatía especial que nos ayude a comprenderlos, o a juzgarlos. Por ejemplo, yo le tengo cariño a Allende. Me parece un personaje que cometió grandes errores y probablemente algunos que nos llevaron a la catástrofe. Pero él fue un hombre que queria hacerle bien a Chile. Lo mismo digo de Pinochet. Fueron personas que tuvieron responsabilidades gigantescas y que tuvieron aciertos y errores como cualquiera de nosotros. [...] Ahora, el caso de Arturo Prat está en otra esfera, en otro nivel. La esencia de sua vida fue el cumplimiento del deber. El no tenía ambiciones ni de honores ni de gloria, solo cumplir con su deber. Eso es lo admirable de su persona ${ }^{12}$.

Com relação ao seu ofício de historiador, Gonzalo é defensor de uma determinada concepção da História na qual acredita-se existir uma objetividade no trabalho do historiador que depende do seu afastamento total de sua visão de mundo. Ao longo de sua trajetória, Vial esteve envolvido em polêmicas com historiadores de esquerda, os quais acusava de realizar um trabalho muito mais ligado à teoria do que ao que ele acreditava que deveria ser a prática historiográfica. Segundo Vial, os historiadores de esquerda

Son personas que tienen su teoria ya lista y acomodan los hechos a ella. Yo soy católico, apostólico y românico, indigno pero practicante, de derecha pura y oligárquica, con todos los prejuicios que ello conlleva, pero me trato de desprender de eso para establecer la verdad histórica (GONZÁLEZ, 2017, p. 112).

Enquanto intelectual, Gonzalo nunca aceitou a etiqueta de "conservador" que lhe foi dada por seus pares acadêmicos. Entre os anos de 1984 e 1986, esteve envolvido em um debate acadêmico com o historiador Cristián Gazmuri, que respondeu o seu artigo “Decadencia, consensos y unidad nacional em 1973”, no qual Vial expunha sua tese sobre o golpe de 1973. Para Gonzalo Vial, o principal que havia de se questionar no artigo de Gazmuri (1985), intitulado "Las tesis historiográficas de Don Gonzalo Vial” era a acusação de ser um historiador conservador. De acordo com Vial, tal conceito nunca foi muito bem definido por conta de três fatores principais: a etiqueta do conservadorismo desqualifica a priori o que diz o historiador; tal conceito pode ser confundido com o conservadorismo político do Chile, que para o autor não significa a mesma coisa com

12 CORREA, G. V. Entrevista a Gonzalo Vial Correa [19 de outubro, 2007] Chile: Revista Capital. Entrevista concedida a Patricia Arancibia. Disponível em: Último acesso em 07 de fevereiro de 2019. 
relação ao trabalho historiográfico, e porque taxar um historiador de conservador leva a um pensamento a priori do que o historiador necessariamente pensa (VIAL, 1968).

A principal obra de Gonzalo Vial foram os cinco tomos de Historia de Chile, la sociedad chilena en el cambio de siglo (1881-1973)13. O objetivo do historiador era "por un lado, explicar el fracaso del régimen democrático en Chile en 1973 y, por outro, señalarles a los políticos cuál fue la enfermedad congénita, oculta y fatal que mato a la democracia chilena" (GONZÁLEZ, 2017, p. 113). De acordo com Vial, na época em que iniciou seus estudos sobre o século $\mathrm{XX}$, não havia nenhum outro historiador que se debruçasse sobre esse período da história chilena. A última história geral sobre o Chile realizada por Francisco Antonio Encina abrangia apenas até a guerra civil de 1881, por isso seu projeto começava de 1881 em diante. Gonzalo destaca que sua intenção era apontar os elementos históricos para que outras pessoas pudessem discutir porque aconteceu o golpe em 1973. Para o historiador, esse era um tema que deveria ser melhor desenvolvido por sociólogos e cientistas políticos ${ }^{14}$. Entretanto, o historiador Mario Andrés sustenta a tese de que, na verdade, essa publicação tinha interesses relacionados à consolidação do projeto ditatorial:

Lo curioso es que el primer volumen de Historia...fue publicado el mismo año en que comenzó a regir la nueva Constitución de la República, en la que se estableció un período de conducción de régimen de facto, bajo el supuesto de que triunfarían en el plebiscito de 1988, de casi veinte años, justamente, las dos décadas que Vial requería, como hemos visto, para concluir la explicación del golpe de Estado de 1973. Coincidencia o no, lo certo es que un período de esas dimensiones era necesario para estabelecer una nueva hegemonía (GONZÁLEZ, 2017, p. 116).

A tese central de sua série de livros se baseava na ideia de que a ruptura política que ocorreu em 1973 foi gerada pela quebra da unidade nacional. Essa unidade só era possível a partir de um consenso, definido pelo autor como:

(...) Son ideas de patria, de nacionalidad, de tradición histórica y cultural, de familia, de educación, de propiedad, de juridicidad, de inalienables derechos de la persona humana y de las minorías, etc. Ideas que el tiempo, las razas progenitoras, la cultura, la Historia, han entretejido con el ser de Chile y con la

\footnotetext{
${ }^{13}$ O primeiro volume foi publicado em 1981, já o último em 2001.

14 Depoimento cedido ao documentário "Gonzalo Vial: un historiador conservador". Disponível em <https://www.youtube.com/watch?v=b8yGGeEg_lo> Último acesso em 07 de junho de 2020.
} 
idiosincrasia de los chilenos, de tal modo que no puede desarraigarlas ninguna ley, ninguna ideologia, ninguna revolucion...son ya nuestra naturaliza (TEIXEIRA, 2015, p.49).

Essa ideia da quebra de consenso permeia também a redação do marco político do Informe, que será analisado posteriormente.

\section{Participação na Comissão}

Gonzalo Vial foi chamado a integrar os trabalhos da Comissão em abril de 1990, quando três outras importantes figuras da direita haviam recusado participar ${ }^{15}$. De acordo com o historiador, ele considerava importante a participação de alguém que não estivera do lado dos "vencedores", alguém de fora da Concertación. Foi dele a exigência de que o período abarcado pela Comissão não se restringisse apenas aos anos de 1973 a 1990. A análise dos casos de mortes investigados pela comissão se restringiria a tal período, porém, para o historiador era preciso estender o recorte temporal para uma compreensão global do fenômeno da violência política (CAVALLO, 1998, p.22). Com essa exigência, o autor conseguiu incluir no Marco Político do Informe os antecedentes do golpe, construindo assim uma narrativa oficial sobre o período iniciado em 1970 com a eleição de Salvador Allende.

Alguns outros pontos sobre a atuação de Vial dentro da Comissão merecem ser destacados. O intelectual foi um dos que defendeu que não fossem informados os nomes dos perpetradores, para que a Comissão não pudesse ser acusada de ter se tornado um tribunal e, juntamente a outros membros, solicitou ao então presidente que este não poderia obrigar ninguém a depor ${ }^{16}$. Em 2007 o historiador inglês Fred Bennetts acusou Gonzalo Vial de ter feito manobras para ocultar a responsabilidade da Marinha em casos apurados pela Comissão. Tal acusação foi publicada pelo jornal Punto Final, tradicional

\footnotetext{
${ }^{15}$ Foram convidados o ex-senador pelo Partido Nacional entre 1969-1977, Francisco Bulnes Sanfuentes, Ricardo Rivadeneira, que havia colaborado com o governo pinochetista e foi um dos fundadores do partido Renovación Nacional e o professor de Direito Civil e ex-conselheiro do Conselho de Defesa do Estado de 1959 até 1989, Guillermo Pumpin. In: CAVALlO, Ascanio. La historia oculta de la transicion. Memoria de una Epoca, 1990-1998. Santiago: Editorial Grualbo S.A., 1998, p.22.

16 “Gonzalo Vial Correa 1930-2009: Historiador y protagonista de un siglo.", La Segunda, Santiago, 30 out. 2009, caderno especial, p. 5. Archivo de Referencias Críticas, Biblioteca Nacional Digital de Chile
} 
jornal de esquerda do Chile, e se baseava em provas recolhidas a partir do Arquivo Rettig. De acordo com Bennetts, foi encontrado nesse arquivo o informe preparado por Pedro Aylwin Chiorrini, advogado responsável pela equipe de investigação da V região com anotações feitas à mão por Gonzalo Vial que alteraram o texto original, suprimindo a parte em que ficava mais evidente a atuação da Marinha durante a Ditadura. Ainda segundo Bennetts, em uma entrevista concedida por Pedro Aylwin, o advogado declarava ter sido deslegitimado pelo encarregado da Comissão que revisou seu texto ${ }^{17}$, o que comprovaria a alegação de Bennetts. Não encontramos nenhuma declaração de Gonzalo Vial sobre o assunto, que ficou restrito a essa denúncia publicada pelo jornal Punto Final.

\section{O Marco Político do Informe}

A partir de agora analisamos comparativamente a narrativa presente no Marco Político com a tese historiográfica desenvolvida por Gonzalo Vial sobre o golpe. Para isso, utilizamos o artigo, "Decadencia, consensos y unidad nacional em 1973” (CORREA, 1984), no qual o autor sistematiza algumas causas da decadência e colapso do sistema político-social vigente no Chile em 1973. Analisamos como o autor enxerga a quebra da democracia e como isso se refletiu na redação do Informe.

Em seu artigo, Gonzalo Vial defende a tese de que na passagem do século XIX para o século XX, o Chile perdeu sua unidade nacional quando se romperam de maneira sucessiva três consensos básicos para essa unidade: o consenso doutrinário, enraizado no catolicismo tradicional de origem hispânico, o consenso político em torno do parlamentarismo, e o consenso social, a aceitação de que apenas uma classe social dirige toda sociedade. A ideia de consenso esteve presente na maior parte da produção historiográfica chilena ao longo do século XX e serviu para reforçar o mito de que haveria no Chile uma exepcionalidade por sua estabilidade político-institucional. Diferentemente

\footnotetext{
${ }^{17}$ BENNETTS, Fred. Falsificador de la historia. La "mano negra" de Gonzalo Vial en el Informe Rettig. Punto Final, 20 de abril de 2007. Disponível em: <http://www.archivochile.com/Chile_actual/columnist/pf_art_edi/pf_art_edi00014.pdf > Último acesso em Último acesso em 07 de junho de 2020.
} 
de autores como o sociólogo Tomás Moulian (1994), que apontam como a ideia de consenso serviu para ocultar os "pés de barro" sob os quais se forjou o sistema democrático chileno, Vial retoma essa noção a partir de um ponto de vista conservador que propõe a construção de novos consensos para garantir a unidade nacional.

Os motivos históricos apontados por Gonzalo Vial para a ruptura desses consensos seriam as "guerras religiosas" entre liberalismo e conservadorismo, o desprestígio do parlamentarismo chileno, originado na ineficácia e corrupção desse sistema político, e a dificuldade da classe dirigente em responder à "questão social" emergente no Chile. A hipótese do autor é a de que essa unidade não se reconstituiu no resto do século, por isso seu colapso em 1973.

Entretanto, o autor também identifica alguns pontos referentes ao período de 1970 que ajudaram a acelerar a queda do regime político-social vigente. Nesse ponto, Vial recorre ao conceito de "planificações globais" do historiador Mário Góngora. As planificações seriam transformações integrais da sociedade segundo um modelo dado e que deveriam acontecer de forma completa e simultânea, já que todas as partes dessa mudança estariam estreitamente interrelacionadas. Para Vial, o problema das "planificações globais" é que os governos que tentaram impor esse tipo de mudança, como foi o caso do governo de Salvador Allende, eram social e politicamente minoritários. Além disso, o autor identifica que em 1973 havia desaparecido dentro do Chile o espírito da tolerância e do pluralismo, que, para ele, seriam dados por um credo comum religioso. Gonzalo Vial destaca ainda a influência da esquerda da Revolução Cubana e das ideias de Che Guevara sobre a inutilidade dos métodos pacíficos e a inevitabilidade do confronto armado.

No texto do Informe também está presente a ideia da quebra do espírito de tolerância e pluralismo, necessários na concepção de Vial para a unidade nacional. O texto inicia falando de uma "aguda polarización a dos bandos - gubernativo y opositores - en las posturas políticas del mundo civil" (CHILE, 1996, p.28). O ponto 1 do Marco Político trata da origem dessa polarização, fala-se da Guerra Fria, da Revolução Cubana e da interferência externa de outros países no Chile. De acordo com a teoria desenvolvida 
no texto, a polarização da Guerra Fria teria ideologizado partidos e movimentos em modelos enrijecidos que não admitiam transações, contribuindo para a polarização. Nesse ponto, o texto trata de dois movimentos mais radicais de esquerda: o Movimiento de Izquierda Revolucionário (MIR) e o Movimiento de Acción Popular Unitaria (MAPU), indicando que havia uma tendência dentro do Partido Socialista chileno a se aproximar desses grupos. Mesmo os que não eram a favor da via armada, ao final da crise estavam caminhando para aceita-la como posição:

\begin{abstract}
Al desenvolverse el período final de la crisis, 1970-1973, estos sectores [Partido Comunista, MAPU Obrero e Campesino, Partido Radical e o próprio presidente Salvador Allende] se vieron desplazados, desbordados y - en ocasiones seducidos y arrastrados por los que postulaban la fatalidade del enfrentamento (CHILE, 1996, p.19).
\end{abstract}

No que diz respeito à direita chilena, o Informe indica que "siempre existió en ella, aunque no en toda ella, una mentalidad propicia a resolver ciertos problemas (algunos de carácter social, por ejemplo, o el del comunismo) mediante el uso de la fuerza" (CHILE, 1996, p.19). O Informe aponta ainda que a única via conciliatória entre governo e oposição naquele momento era a Igreja Católica.

O segundo ponto que narra a situação do Chile em setembro de 1973 apresenta a fase final da polarização e da crise. O texto começa destacando que a ascensão da Unidade Popular ao poder ajudou a acentuar a polarização que já vinha acontecendo no Chile. Outros pontos contribuem para essa polarização, tais como: o papel dos Estados Unidos para acentuar a crise política e econômica chilena e a estratégia da direita para impedir o governo de Salvador Allende. A polarização está posta da seguinte forma no texto:

\footnotetext{
Vía armada" x "ingovernabilidade" vinieron a ser, de tal modo, indicativas de conceptos excluyentes de sociedad, ninguno de los cuales podía imponerse al outro democráticamente; y tampoco se admitía transigir con el adversário, abriendo así camino a una salida pacífica (CHILE, 1996, p.30).
}

A justificativa apresentada para que os partidos opositores partissem para a estratégia da ingovernabilidade é fundamentada na ideia de que as ocupações de terra ocorridas durante o governo da Unidade Popular eram uma violação de direitos percebemos aqui como a defesa da propriedade privada ainda está presente em suas 
formulações. A desordem criada pelas tomadas e retomadas de terra teria contribuído para o avanço da força armada de particulares, enquanto que a polícia não atuava efetivamente nesses casos. Tudo isso, juntamente à "destruição da pessoa moral dos adversários", intensificada pela mídia, teria contribuído para a "inevitabilidade" de um confronto:

El conjunto de los factores que hemos descrito, anteriores y posteriores a 1970, condujo, hacía 1973, a un clima objetivamente propicio a la guerra civil. Esta y aquél significaban aceptar la posibilidad, y quizás la inevitabilidad, de que adversários inocentes fueran sujetos a sufrimientos físicos y morales. Era el precio a pagar por lo que, en el clima de guerra civil, se suponía estar en juego: la vigencia de un modelo de sociedad declarado (por cada bando el suyo) el único aceptable; la preservación de derechos básicos e inalienables; la vida misma..."Ellos o nosostros". "Matar o morir". "Hay que extipar el câncer". "No se puede hacer la tortilla sin quebrar algunos huevos". Fueron entonces frases comunes, que denotaban sentimientos profundos que no podían servir a ninguna convivencia pacífica y, al contrario, preparaban el terreno para el temor que engendra el ódio que conduce a la brutalidade y la muerte (CHILE, 1996, p.32).

Um ponto de intenso debate com relação ao pensamento de Vial é o papel desempenhado pelas Forças Armadas nesse processo de decadência analisado por ele. Para o autor, diante de um conflito civil sem solução foi que as Forças Armadas decidiram intervir. Tanto em seu artigo acadêmico quanto no Informe, o autor defende a ideia de que não existia dentro das Forças Armadas um projeto político para tomar o poder. Ainda que alguns setores tivessem ideias sobre como deveria ser a organização político-social do país, essa não é para Vial a causa principal da intervenção das Forças Armadas. É importante lembrar que essa visão já foi intensamente questionada pela historiografia chilena e parte de um pressuposto teórico que pretende justificar o golpe de 1973, ancorando-se na ideia de que as Forças Armadas se mantiveram neutras até o momento em que foi "necessário" intervir.

Em seu artigo, o historiador analisa a atuação das Forças Armadas durante o governo de Salvador Allende e os pedidos de intervenção que ocorreram. Um dos pontos destacados é a declaração do Partido Democrata Cristão solicitando "un Ministerio con participación institucional de las Fuerzas Armadas, con poderes suficientes, en mandos superiores y médios, para assegurar el efectivo cumplimiento de las decisiones de V.E. 
[o presidente Allende], dentro del marco de la Constitución y de las leys" (CORREA, 1984, p. 141). Gonzalo argumenta também que o próprio Allende patrocinava a ingerência institucional dos militares ao formar primeiramente um ministério composto pelos generais Prats, Huerta e Sepúlveda e, posteriormente, com todos os quatro comandantes em chefe das Forças Armadas.

Para o historiador, a experiência do chamado "gabinete de los comandantes en chefe" é essencial para se entender a intervenção ocorrida em 1973. O gabinete recebeu crítica das três principais forças políticas do Chile: de um lado a democracia cristã criticava pelo fato de o novo ministério não ter tanto poder, por outro lado, a direita considerava que para solucionar o impasse político era necessário um golpe ou pronunciamento das Forças Armadas, enquanto isso, setores mais radicalizados da esquerda viam os militares como inimigos e criticavam duramente a opção feita por Allende. Em 22 de agosto, a Câmara de Deputados adotou um acordo entre o Partido Nacional e o Partido Democrata Cristão contra o gabinete, dias depois eles renunciaram. Para Vial, "desde ese momento, la intervención militar sólo podia tomar la forma de un pronunciamento o golpe de Estado" (CORREA, 1984, p. 145).

Historiadores como Veronica Valdivia Ortiz têm demonstrado como a mudança de posicionamento das Forças Armadas é na verdade um processo histórico que tem raízes anteriores ao governo de Salvador Allende. Segundo a autora, esse movimento se inicia nos anos 40, mas ganha força a partir da experiência do governo do democrata cristão Eduardo Frei. É durante esse período que se abre caminho para uma tendência antidemocrática que poderia dar corpo a um projeto político de largo alcance (VALDIVIA, 1996).

Gonzalo Vial realiza, portanto, uma análise que, ao partir do governo de Salvador Allende, pretende fomentar a tese de que as Forças Armadas estiveram acuadas diante de dois pólos, a esquerda e a direita, e por isso decidiram intervir. Essa teoria pretenderia portanto justificar a ação dos militares, ignorando que existia uma tendência golpista dentro das Forças Armadas desde antes do governo da Unidade Popular. Vial ainda traz mais um elemento que justificaria a intervenção militar: a divisão feita tanto pela esquerda 
quanto pela direita entre um setor "golpista" dentro das Forças Armadas e um setor "legalistas". Em seu artigo, Gonzalo Vial declara:

Es posible que hubiese mayor simpatia castrense, en términos generales, hacia la oposición que hacia el allendismo; es posible que éste despertara antipatia en la oficialidade por sus aspectos de desorden, indisciplina, antimilitarismo tradicional en la Izquierda -, menosprecio de las glorias pátrias, etc. Pero el golpe de Estado no se dio por nada de ésto, sino por las razones más de peso que hemos referido (CORREA, 1984, p. 145).

Assim como no Informe:

Enumerados así los diversos factores, en gran medida ajenos a las Fuerzas Armadas y de Orden, que las indujeron a intervenir en septiembre de 1973, no podría decirse, sin embargo, que ellos fueran las únicas causas de tal intervención. Idudablemente fue así para el conjunto y gran mayoría de ellas. Pero los hechos posteriores, que analizaremos de inmediato, tampoco parecen dejar dudas de que, adicionalmente, existía al interior de las Fuerzas Armadas y de Orden una corriente ideológica caracterizada (quizás) por algunas nociones más bien vagas y simples sobre lo que debía ser la organización, política social y económica del país, pero sobre todo por un concepto extremo y extraviado de la guerra antisubversiva en relación con la seguridad nacional (CHILE, 1996, p.35).

O texto do Informe ressalta também o apoio público que as Forças Armadas tinham no momento do golpe:

Contaban las Fuerzas Armadas y de Orden con un alto apoyo público, en parte fomado por seguidores convencidos y fervorosos, en parte por quienes pensaban que 'no existía otra salida', y en parte por quienes carecían de ideas definidas, pero deseaban 'vivir tranquilos', sin los sobresaltos y privaciones de los últimos días del régimen depuesto (CHILE, 1996, p.36).

O historiador destaca que existiam contradições internas sobre qual regime político seria implantado com a deposição de Salvador Allende. De acordo com a redação do Informe, a duração da intervenção era um ponto de discussão dentro das forças armadas. Existiam aqueles que acreditavam que deveria ser uma intervenção breve, outros que defendiam a existência de metas, não de prazos, a serem cumpridas pelo novo regime e outros que acreditavam em uma intervenção permanente. Progressivamente, o grupo que mais tinha coesão interna, que era o que estava dentro do exército, foi ganhando espaço no novo governo. A coerência ideológica e de ação desse grupo teria sido o fator determinante para o problema dos direitos humanos. 
A partir desse ponto, o Informe analisa a doutrina de contra-insurgência, central para os problemas de direitos humanos ocorridos, propagada a partir das diversas escolas de alistamento militar dos Estados Unidos e que entendia os focos de guerrilha que começaram a surgir no continente americano após a Revolução Cubana como uma verdadeira guerra. Tal guerra acontecia não só no âmbito interno de cada país contra seus insurgentes, mas em nível continental era uma guerra dirigida por Cuba, apoiada pela União Soviética, contra as instituições do mundo livre. O ponto central dessa doutrina é que ao defender que a guerrilha, não respeitava nenhuma lei bélica ou moral, a doutrina autorizava a contra-insurgência a responder à guerrilha utilizando seus mesmos métodos:

La doctrina de la contrainsugencia se reflejó, en diversos grados, sobre las enseñanzas recibidas y las prácticas inculcadas en los entrenamientos de la lucha antiguerrillera. El secreto de las operaciones; las "técnicas de interrogatorio"; la educación en formas de lucha y de muerte "especiales" y para tender emboscadas; los adiestramientos "de supervivencia", que a menudo incluían realizar actos degradantes para la propia dignidad, o crueles, etc., iban acostumbrando a los alumnos a que los límites éticos fuesen retrocediendo o desvaneciéndose, hasta desaparecer (CHILE, 1996, p.38).

O segundo ponto analisado nessa parte trata da atuação do chamado "grupo DINA". Nesse ponto, é importante lembrar que foi após os assassinatos de Orlando Letelier e Ronnie Moffitt em solo norteamericano, liderado pelo chefe da DINA Manuel Contretas, que a postura tanto de Vial quanto dos outros editores da revista Qué Pasa mudou com relação aos crimes cometidos pela Ditadura:

\footnotetext{
El semanário y los civiles vinculados a la revista, neoliberales y gremialistas, habían visto un problemático obstáculo en la DINA, por todo lo que hemos detallado [o autor se refere à pressão norteamericana sobre o caso Letelier]. Si bien era certo que para este sector no era posible hacer desaparecer los organismos de inteligência del régimen, lo menos que se podia hacer era vincularlos con la figura de Pinochet. En esse sentido, Contreras servía como un chivo expiatório para desresponsabilizaral régimen por las atrocidades consumadas por la DINA (GONZÁLEZ, 2017, p.77).
}

O Informe identifica o "grupo DINA" como sendo o grupo de majores e coronéis do Exército que começou a atuar na Escola Militar ainda em 1973 e, posteriormente, dentro da Dirección de Inteligencia Nacional (DINA). A atuação desse grupo é 
caracterizada pelo seu extremismo e seu objetivo principal era a eliminação da "ultraesquerda" chilena, identificada no MIR e grupos próximos a esse movimento. Ao analisar a relação entre a DINA e as Forças Armadas como um todo, o Informe estabelece algumas possíveis respostas para a não intervenção das Forças Armadas para deter a ação da DINA. A primeira explicação dada é a falta de conhecimento por parte das Forças Armadas do que ocorria. De acordo com o texto, o grupo era secreto e grande parte dos oficiais desconhecia o que de fato acontecia. Outro ponto ressaltado é o de que havia provavelmente uma zona intermediária da oficialidade que pensava que os movimentos de esquerda atingidos pela repressão brutal da DINA mereciam tal destino e que as mortes de militantes eram fruto de enfretamentos reais, ainda que nesses enfrentamentos o cumprimento da lei fosse mínimo por parte dos grupos oficiais do Exército. Novamente, o texto destaca a desinformação em que vivia grande parte da oficialidade, facilitando assim a disseminação de versões parcializadas dos acontecimentos (CHILE, 1996, p.39$40)$.

O texto prossegue apresentado mais quatro explicações para essa questão: a ideia de que ambos os lados estavam em guerra, fomentada até finais de 1974, tornou a DINA um "mal necessário"; a justificativa de que enfrentar a realidade do que acontecia prejudicaria a imagem do Chile; outra explicação apresentada é a de que não existia na oficialidade um conhecimento adequado das leis morais e bélicas, e, por último, o que teria ajudado na consolidação e impunidade do grupo da DINA teria sido sua capacidade de manobra dentro dos institutos militares, o que permitia a eles paralisarem ou acabarem com a carreira profissional daqueles que se opunham. A centralização do regime no Exército é destacada também como um ponto que favoreceu a atuação desse grupo.

Apesar de o Informe destacar que a Comissão não tentou justificar a atuação do grupo, mas sim explicar o que permitiu que tais violações acontecessem (CHILE, 1996, p.40), percebemos que existe uma tentativa de centralizar todos os "excessos" cometidos pelo regime como sendo de responsabilidade da DINA e, dessa forma, reabilitar a imagem das Forças Armadas em geral. A recorrente justificativa apresentada pelo Informe de que nem todos os militares sabiam o que acontecia nos parece confirmar essa hipótese. Na 
verdade, a DINA fazia parte do aparato repressivo da Ditadura que contava ainda com a manipulação e ocultamento do que ocorria por meio dos principais jornais ${ }^{18}$ para manter a aparente legalidade da Ditadura. Além disso, é importante destacar o papel central da DINA na formulação da Operação Condor que organizou a cooperação na repressão entre os países do Cone Sul, juntamente à Bolívia e ao Paraguai. De acordo com a historiadora Samantha Quadrat (2002), aparentemente foi o general Manuel Contreras, chefe da DINA, que teria sido o idealizador da Operação.

O Informe destaca ainda uma suposta contradição entre o discurso proclamado pela Ditadura Militar pós-1973 e a atuação da DINA:

\begin{abstract}
Producido el 11 de septiembre, se generó casi de imediato la contradicción que la sola presencia del grupo DINA, y su creciente influjo debían necesariamente significar. Por una parte, el régimen llamaba a la unidad nacional y a una labor colectiva, de la cual nadie estaría excluído, para reconstruir el país y avanzar en el camino del desarrollo. Este llamado, naturalmente, atraía a muchíssimos, inclusive a partidarios desencantados del Gobierno depuesto. Pero, paralela y secretamente, la acción del grupo DINA implicaba la negación absoluta de la unidad de los chilenos todos, a la cual se convocaba (CHILE, 1996, p.41).
\end{abstract}

A contradição explicitada nesse trecho do Informe é, porém, apenas aparente. O chamado para "unidade nacional" feito pela Ditadura Militar excluía todos aqueles que fossem contrários às ideias do regime e, portanto, a DINA, com sua política de extermínio, fazia parte da política autoritária da Ditadura.

Quanto à atuação dos civis durante o regime militar em matéria de Direitos Humanos, o Informe declara que "ellos sin duda supieron del problema, y de la nocividad del grupo [DINA], pero, em general, carecieron de instrumentos para abordar eficazmente la situación, y juzgarón más perjudicial que beneficioso abandonar, por ella, su apoyo global al régimen militar" (CHILE, 1996, p.43).

\footnotetext{
${ }^{18} \mathrm{Um}$ dos casos mais emblemáticos foi a atuação do jornal La Segunda na Operação Colombo. O jornal divulgou informações sobre um suposto enfrentamento interno entre militantes do MIR que teria resultado na morte de 59 integrantes que, na verdade, haviam sido assassinados pela Ditadura. Sobre o assunto, ver: http://www.eldesconcierto.cl/2018/09/11/exterminados-como-ratones-4-portadas-con-las-que-elmercurio-defendio-la-dictadura/ e https://politica.estadao.com.br/noticias/eleicoes,jornal-deu-novaversao-para-mortes-no-chile-imp-, 1165490 Último acesso em 04 de dezembro de 2018.
} 
O grupo reunido em torno da DINA só começou a ser dissolvido em 1978, após o caso Letelier. A DINA, enquanto organismo de estado, foi substituída pela Central Nacional de Informaciones (CNI) que, apesar de ser dirigida por um oficial do Exército contrário ao grupo anterior, conservou muitos nomes que estiveram na DINA. O Informe destaca o retorno de ações insurrecionais por parte do Partido Comunista e do MIR com o fim da DINA, encerrando dessa forma o seu Marco Político. De acordo com Mario Andrés González,

\begin{abstract}
La verdad es que el Informe de la Comisión que se hizo público en febrero de 1991, no constituyó una acusación directa contra las Fuerzas Armadas como institutos. Es más, antes de individualizar las víctimas de la violência política, Vial se preocupo de elaborar un contexto histórico político en función de situar la acción de las Fuerzas Armadas, con lo cual no hacía más que responsabilizar de forma indirecta la izquierda de la masacre que emergió con la dictadura, si bien insistió en que no quería decir tal cosa. El Informe de la Comisión, además de indagar sobre las violaciones de los derechos humanos con resultado de muerte, tenía como objetivo constituirse en un dispositivo histórico que alertara sobre las condiciones que podían hacer posible el contexto social en el que sobrevino el gobierno de la Unidad Popular (GONZÁLEZ, 2017, p. 179).
\end{abstract}

Apesar de não fazer uma defesa explícita do golpe, o Marco Político do Informe levanta diversos fatores para justifica-lo, a própria ideia da quebra de consenso, tese central de Gonzalo Vial, mas também outros fatores, como a ameaça que a tomada de terras representava para a propriedade privada e a radicalização da esquerda em decorrência da Revolução Cubana. Longe de realizar uma análise crítica sobre a real influência desses fatores, o Informe parece querer encerrar a discussão sobre o que gerou o golpe de 1973, apoiando-se na tese que reforça sua inevitabilidade. De acordo com o historiador Greg Grandin (2014, p. 19-50), apenas no Informe da Comissão chilena é que a História ganha centralidade: "recorreu-se à história aqui para fornecer justificativa para a inexorabilidade da intervenção militar" (GRANDIN, 2014, p. 35).

A visão conservadora de Gonzalo Vial sobre o golpe de 1973 foi utilizada pelo governo da Concertación para alcançar a reconciliação e formar uma memória oficial sobre o período do governo da Unidade Popular que apontasse a radicalização política como causa central do golpe. Dessa forma, a narrativa historiográfica desenvolvida por Vial serviu durante anos para alimentar uma determinada memória do golpe. 


\section{Considerações Finais}

Seria importante para o nosso argumento destacar as possíveis disputas dentro da Comissão sobre o texto do Marco Político do Informe. Entretanto, a documentação interna da Comissão, como suas atas de reunião, não está ainda disponível para acesso. Vale, porém, mencionar que os oito comissionados ${ }^{19}$ convocados por Patricio Aylwin não formavam um grupo homogêneo. Um dos integrantes da Comissão, o advogado José Zalaquett destaca que "cuatro de los ocho miembros habían sido "partidarios" del gobierno militar o del derrocamiento de Allende -pero no de las violaciones a los derechos humanos- y otros cuatro, defensores de los derechos humanos y opositores al gobierno de facto de Pinochet" ${ }^{\prime 20}$. A partir dessas informações sobre o perfil dos integrantes da Comissão, podemos levantar a hipótese de que a tese de Vial não obteve o apoio total de todos os integrantes, ainda que tenha sido escolhida para compor o texto final do Informe.

A escolha dessa perspectiva de análise sobre o golpe de 1973 pode ainda ser justificada pelo papel do Partido Democrata Cristão ao longo do governo de Salvador Allende. O próprio presidente Patricio Aylwin, assim como outros membros da Comissão, haviam sido apoiadores do fim do governo da Unidade Popular, ainda que não tenham apoiado a Ditadura Militar que se instaurou a partir do golpe. Dessa forma, a tese da inevitabilidade defendida por Vial justificava não só a atuação dos militares em 1973, mas de outros atores políticos que contribuíram para a queda de Allende.

Essa narrativa que busca um constante equilíbrio entre prestar contas sobre o passado de violações sem atacar diretamente o governo anterior pode ser vista como um modelo do Chile pós-ditadura e relaciona-se com o tipo de transição adotado no país (AZCÁRRAGA, 2009). É importante destacar que o ex-ditador Augusto Pinochet manteve-

\footnotetext{
${ }^{19}$ Raúl Rettig, Jaime Castillo Velasco, José Zalaquett, José Luis Cea, Ricardo Martíns Dias, Mónica Jímenez de la Jara, Laura Novoa Vásquez e Gonzalo Vial.

${ }^{20}$ Entrevista a José Zalaquett no programa televisivo "Secretos del Informe Rettig", Ahora Noticias, Mega, transmitido ed 3 de 12 marzo de 2016 apud HOURCADE et. al. Comisiones de la Verdad de Chile: Verdad y Reparaciones como Política de Estado. Informe de CMI, n. 14, outubro de 2018, p. 9.
} 
se presente no cenário político chileno inicialmente como Comandante em Chefe do Exército e depois como senador vitálicio, o que também contribuiu para a construção de uma memória reconciliadora.

Apesar de existirem diversas outras versões sobre o golpe ${ }^{21}$, é importante lembrar que, por ser um documento de Estado, o Informe teve uma importância central para a construção da memória social sobre o golpe. O texto do Marco Político do Informe foi indicado como uma das leituras sugeridas para revisar as interpretações do golpe de Estado pelo marco curricular de História e Ciências Sociais aprovado em 1996 para o ensino básico e em 1998 para o ensino médio (REYES, 2004). De acordo com a historiadora Samantha Viz Quadrat, o ensino de História nos permite identificar as disputas de memória presentes em uma sociedade e, no caso chileno, a estratégia utilizada pelo governo da Concertación de tratar o golpe como "inevitável” gerou insatisfação por parte de diversos setores sociais (QUADRAT, 2015, p. 282). A pesquisadora Leonora Reyes expõe os problemas do texto utilizado em materiais didáticos produzidos pelo governo:

\begin{abstract}
Al centrarse en el clima de polarización reinante previo al golpe de Estado de 1973, los materiales educativos considerados (programas de estúdio, libro de texto) evitan responsabilizar a las Fuerzas Armadas por haber ejecutado ese golpe, silenciam las dimensiones explicativas que aporta el tiempo largo y el análisis de orden estructural, y finalmente olvidan la posibilidad de llamar dictadura al gobierno militar, y golpe de Estado a la irrupción de los militares en el poder (REYES, 2004, p. 78).
\end{abstract}

O historiador Mario Gárces, que faz parte de uma nova geração de historiadores chilenos ligados à esquerda e que buscaram apontar os problemas do processo de transição, destaca que o argumento central do Marco Político do Informe esteve presente também, embora com algumas nuances, nas ciências políticas, tendo progressivamente se tornado a narrativa oficial da imprensa chilena:

Esta línea de argumentación, centrada en la noción de "polarización" y "modelos completos" (la versión original de la historiografia conservadora fue "planificaciones globales"), se fue constituyendo en uma suerte de sentido

\footnotetext{
${ }^{21}$ Indicamos o estudo desenvolvido por Alberto Aggio sobre o tema: AGGIO, Alberto. Democracia e socialismo: a experiência chilena. São Paulo Annablume, 2002.
} 
común para los medios de comunicación (la polarización) y para las ciencias sociales y políticas (las planificaciones globales) (GÁRCES, 2010, p.155).

A interpretação historiográfica de Gonzalo estava de acordo com a proposta de "reconciliação" da Comissão, fazendo com que a historiografia funcionasse nesse momento como "fonte produtora (e legitimadora) de memórias e tradições, chegando mesmo a fornecer credibilidade cientificista a novos mitos de (re) fundação de grupos e da própria nação" (CATROGA, 2015, p.50). Em um momento no qual o Chile ainda encontrava-se extremamente dividido e o temor de um novo golpe era constante dentro da sociedade, a narrativa da "quebra de consenso" fazia parte de uma política de memória que buscava tratar desse período sem trazer de volta ao presente as fissuras e disputas políticas do passado.

\section{Referências Bibliográficas}

AGGIO, Alberto. Democracia e socialismo: a experiência chilena. São Paulo Annablume, 2002.

AZCÁRRAGA, Barbara. Memoria e Historiografia. Los usos públicos de la memoria durante la posdictadura Chile 1990-2006. 2009. Tese (licenciatura em História) Pedagogia em História e Ciências Sociais, Universidade de Valparaíso, Valparaíso, Chile.

BAUER, Caroline. Como será o passado? História, historiadores e a Comissão Nacional da Verdade. São Paulo: Paco Editorial, 2017.

BAUER, Caroline e NICOLAZZI, Fernando. O historiador e o falsário. Varia Historia, Belo Horizonte, vol. 32, n. 60, set/dez 2016, pp. 807-835.

CATROGA, Fernando. Memória, História e historiografia. Rio de Janeiro: Editora FGV, 2015.

CAVALlO, Ascanio. La historia oculta de la transición. Memoria de una época, 19901998. Santiago: Editorial Grualbo S.A., 1998.

CORREA, Gonzalo. Decadencia, Consensos y Unidad Nacional en 1973. Dimensión Histórica de Chile, n. 1, 1984.

3, 1968, pp. 241-257.

Alrededor de los sucesos de 1973. Dimensión Histórica de Chile, n. 
GÁRCES, Mario, GARCÉS, Mario. Actores y disputas por la memoria en la transición siempre inconclusa. Ayer, n. 79, 2010, pp. 147-169.

GAZMURI, Cristián. Las Tesis historiográficas de don Gonzalo Vial. Opciones, n.6, maio-agosto, 1985, p. 147-162.

GONZÁLEZ, Mario. Gonzalo Vial Correa. Las sinuosidades de una trayectoria intelectual, 1969-1991. Santiago: RIL Editores, 2017.

GRANDIN, Greg. A instrução da grande catástrofe: Comissões da Verdade, história nacional e formação do Estado na Argentina, Chile e Guatemala. Ponto-e-vírgula, n. 15, 2014, pp. 19-50.

LOVERMAN, Brian; LIRA, Elizabeth. Las ardientes cenizas del olvido: vía chilena de Reconciliación Política 1932-1994, Santiago: LOM Ediciones, 2000.

MOULIAN, Tomás. Limitaciones de la transición a la democracia en Chile. Proposiciones, n. 25, 1994, p. 25-33.

ORTIZ, Veronica. Nacionales y gremialistas: el "parto" de la nueva derecha política chilena, 1964-1973. Santiago: LOM Ediciones, 2008.

QUADRAT, Samantha. Operação Condor: o "Mercosul" do terror. Estudos IberoAmericanos, v. 28, n. 1, junho 2002, p. 167-182.

Páginas da História. O ensino das ditaduras do Cone Sul. In: MOTTA, Rodrigo Patto Sá (org.). Ditaduras militares: Brasil, Argentina, Chile e Uruguai. Belo Horizonte: Ed. UFMG, 2015, pp. 277-291.

REYES, Leonora. Actores, conflito y memoria: reforma curricular de historia y ciências sociales en Chile, 1990-2003. In: JELIN, Elizabeth; LORENZ, Federico (Comp.). Educación y Memoria: la escuela elabora el pasado. Buenos Aires Siglo XXI, 2004, pp. 65-93.

SUBERCASEAUX, Bernardo. Editoriales y círculos intelectuales en Chile 1930-1950. Revista Chilena de Literatura, n. 72, abril 2008, pp. 221-233.

TEIXEIRA, Fernanda. Batalhas pela memória: Verdade, reparação e justiça nas narrativas históricas e fílmicas sobre a ditadura (1973-2015). 2015. Dissertação (Mestrado em História). Instituto de Ciências Humanas e Sociais, Universidade Federal de Ouro Preto. 
VALLEJOS, Julio. La historiografía chilena durante el siglo XX. Cien años de propuestas y combates. Valparaiso: América en Movimiento, 2016.

VALDIVIA, Verónica. Camino al golpe: el nacionalismo chileno a la caza de las Fuerzas Armadas. Santiago: Serie de Investigaciones, 1996.

VIAL, Gonzalo. Alrededor de los sucesos de 1973. Dimensión Histórica de Chile, n. 3, 1968, pp. 241- 257. 